$$
\text { CONF- } 96 / 009--5
$$

\title{
An Investigation of the Electrical Behavior of Thermally-Sprayed Aluminum Oxide
}

\author{
C.J. Swindeman, R.D. Seals, and R.L. White \\ Engineering Technology Division \\ Oak Ridge National Laboratory \\ Oak Ridge, TN USA
}

\author{
W.P. Murray and M.H. Cooper \\ Instrumentation and Controls Division \\ Oak Ridge National Laboratory \\ Oak Ridge, TN USA
}

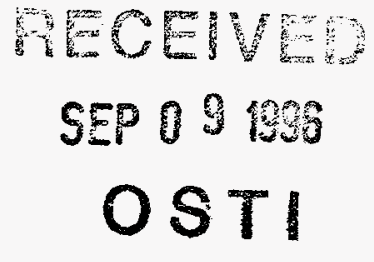

\begin{abstract}
Electrical properties of plasma-sprayed aluminum oxide coatings were measured at temperatures up to $600{ }^{\circ} \mathrm{C}$. High purity ( $>99.5 \mathrm{wt} \%$ pure $\mathrm{Al}_{2} \mathrm{O}_{3}$ ) alumina powders were plasmasprayed on stainless steel substrates over a range of power levels, using two gun configurations designed to attain different spray velocities. Key electrical properties were measured to evaluate the resultant coatings as potential insulating materials for electrostatic chucks (ESCs) being developed for semiconductor manufacturing. Electrical resistivity of all coatings was measured under vacuum upon heating and cooling over a temperature range of 20 to $600{ }^{\circ} \mathrm{C}$. Dielectric constants were also measured under the same test conditions. X-ray diffraction was performed to examine phase formation in the coatings. Results show the importance of powder composition and careful selection and control of spray conditions for optimizing electrical behavior in plasma-sprayed aluminum oxide, and point to the need for further studies to characterize the relationship between high temperature electrical properties, measured plasma-spray variables, and specific microstructural and compositional coating features.
\end{abstract}

THERMAL SPRAYING is attracting considerable interest as a method for depositing economical high performance dielectric coatings for semiconductor applications. One such application that has gained increasing attention over the past several years is the development of thermal spraying for manufacturing electrostatic chucks (ESCs). ESCs can lower semiconductor manufacturing costs by reducing wafer bowing, particle contamination, and other disadvantages associated with mechanical clamping [1,2]. ESCs for etching, implantation, physical vapor deposition (PVD), and chemical vapor deposition (CVD) have been explored and implemented with varying degrees of success $[3,4]$. A particular challenge is the development of dielectric coatings that will allow ESCs to function in higher temperature wafer processing environments (up to $600^{\circ} \mathrm{C}$ ).

In the simplest ESC design, an insulating layer such as a ceramic coating applied to the lower electrode controls the charge separation between the wafer and chuck. Electrical properties that determine the effectiveness of this layer are the dielectric constant, electrical resistivity, and the dielectric strength. Dielectric constant should be high enough that the applied voltage required to sustain the needed clamping pressure does not result in dielectric breakdown. Electrical resistivity is particularly important relative to high temperature performance, as the resistivity for most ceramics typically decreases exponentially with increasing temperature, while the dielectric constant increases very slowly. In alumina, - a desirable candidate ESC coating material - volume resistivity can be as high as about $10^{15} \Omega-\mathrm{cm}$ at room temperature [5]. The presence of impurities (particularly alkaline metal ions such as sodium) significantly lowers electrical insulating ability, especially as temperature increases. In the temperature range of interest for high temperature ESCs $\left(200-600^{\circ} \mathrm{C}\right)$, resistivity of $\alpha$-alumina has been shown to be dominated by ionic conduction, with electronic conduction being fairly insignificant [6]. While there are considerable data available on the electrical behavior of alumina in the sintered or "bulk" form (especially at low and very high temperatures $>1000{ }^{\circ} \mathrm{C}$ ), little has been reported on this behavior relative to thermally-sprayed alumina at moderate temperatures.

This study was undertaken to investigate the electrical behavior of plasma-sprayed alumina in the temperature range of interest for high temperature ESCs. In plasma-sprayed alumina, a host of physical and compositional features influenced by the feedstock and process conditions are expected to contribute to coating electrical behavior, including the type and distribution of additive compounds and impurities, stoichiometry and phase content, and the size, shape, and distribution of splats, grains, porosity and other defects [7-9]. 


\section{DISCLAIMER}

This report was prepared as an account of work sponsored by an agency of the United States Government. Neither the United States Government nor any agency thereof, nor any of their employees, makes any warranty, express or implied, or assumes any legal liability or responsibility for the accuracy, completeness, or usefulness of any information, apparatus, product, or process disclosed, or represents that its use would not infringe privately owned rights. Reference herein to any specific commercial product, process, or service by trade name, trademark, manufacturer, or otherwise does not necessarily constitute or imply its endorsement, recommendation, or favoring by the United States Government or any agency thereof. The views and opinions of authors expressed herein do not necessarily state or reflect those of the United States Government or any agency thereof. 


\section{DISCLAIMER}

Portions of this document may be illegible in electronic image products. Images are produced from the best available original document. 
The effects of these factors on electrical performance are further complicated by other practical considerations related to the end use of the coating, such as the substrate material and operating environment. While all of these factors should be considered in the development and optimization of an alumina ESC coating, the scope of this study was limited to a preliminary investigation of the relationship between a number of commercially available powders, selected process conditions, and measured coating properties. The work described in this paper is a continuation of initial work in which electrical properties measurement procedures were devised, promising candidate powders and process conditions were identified, and small-scale ESCs were fabricated and tested [10]. Here, a smaller range of high purity alumina powders were sprayed using a limited range of process variations and the resultant coatings examined in relation to high temperature electrical behavior.

\section{Experimental Procedure}

Three alumina powders were down-selected for use in this study, following a preliminary evaluation of sprayability and resultant electrical properties of coatings sprayed using a larger range of alumina powders from various suppliers. Specifications corresponding to one lot each of powders " $\mathrm{a}$," "b," and "c" are shown in Table 1. Compositions shown in the table for powders "a" and " $b$ " were determined using Inductively Coupled Plasma (ICP) analyses. The composition shown for powder " $c$ " is from the manufacturer's specification.

Table 1: Specifications for $\mathrm{Al}_{2} \mathrm{O}_{3}$ powders

\begin{tabular}{|c|l|}
\hline Powder & \multicolumn{1}{|c|}{ Purity (wt \% or ppm) } \\
\hline$a$ & $\begin{array}{l}99.9 \mathrm{Al}_{2} \mathrm{O}_{3}, 720 \text { ppm Ti, <120 ppm } \mathrm{P}, \\
<12 \mathrm{ppm} \mathrm{Na}, \text { others }<20 \text { ppm each }\end{array}$ \\
\hline b & $\begin{array}{l}99.99 \mathrm{Al}_{2} \mathrm{O}_{3},<11 \mathrm{ppm} \mathrm{Ti},<160 \mathrm{ppm} \mathrm{P}, \\
<26 \mathrm{ppm} \mathrm{Na} \text { others }<26 \text { ppm each }\end{array}$ \\
\hline c & $\begin{array}{l}99.59 \mathrm{Al}_{2} \mathrm{O}_{3}, 0.35 \mathrm{Na}_{2} \mathrm{O}_{3}, 0.03 \mathrm{Fe}_{2} \mathrm{O}_{3}, \\
\\
0.03 \mathrm{SiO}_{2}\end{array}$ \\
\hline
\end{tabular}

Plasma-spraying of each powder was conducted using a Miller Thermal 4500 plasma-spray system and an SG-100 gun mounted on a robot. Coatings were deposited on grit-blasted $304 \mathrm{~L}$ stainless steel coupons $5.08-\mathrm{cm}$ in diameter $\mathrm{x} 0.51-\mathrm{cm}$ thick, and on $2.54-\mathrm{cm} \times 1.27-\mathrm{cm} \times 0.3-\mathrm{mm}$ thick coupons. To examine the sensitivity of coating electrical behavior to selected spray process conditions, the powders were sprayed using two different gun configurations over a range of power levels. Each powder was sprayed using two different anode/cathode combinations which are commercially described as "subsonic" and "Mach I" gun configurations, and are designed for attaining relatively lower and higher gas and particle velocities, respectively. No attempt to minimize metastable phase formation by controlling the substrate temperature was made, since this could not be performed with other low melting point candidate substrate materials. A total of six different sets of coupons were sprayed for each powder, using the two gun set-ups and power levels ranging from -25 to $60 \mathrm{~kW}$. Argon was used as the carrier gas, and the plasmaforming gases were argon and helium. The stand-off distance was $7.6 \mathrm{~cm}$ for all samples. All coatings deposited on the round coupons were polished using a water-based diamond slurry on a ceramic polishing platen to attain a target surface roughness of $<1 \mu \mathrm{m} R_{\mathrm{a}}$. The effect of this polishing method on overall coating purity appeared to be minimal, based on an earlier evaluation [10]. The polished coatings were rinsed and dried, and average coating thicknesses were obtained using an eddy-current measurement method.

$\mathrm{X}$-ray diffraction of coatings deposited on the rectangular coupons under each set of conditions was performed to examine phase contents. Continuous scans were performed using a Scintag Pad V diffractometer from 10 to 70 degrees $2 \theta$ using $\mathrm{Cu} \mathrm{K} \alpha$ radiation $(\lambda=1.54060 \mathrm{~A})$. A scan rate of 0.8 degrees/min was used to yield a detectability limit of about 5 percent.

To measure electrical properties, coated coupons were sandwiched between $5.715-\mathrm{cm}$ diameter $\mathrm{x} 0.51-\mathrm{cm}$ thick stainless steel electrodes. The sample and electrodes were loaded in a vacuum furnace which was typically operated at a pressure of $5 \times 10^{-6}$ Torr. A quartz sheath was placed over the sample fixture to protect samples from potential contaminants in the furnace environment. To measure dielectric constant and electrical resistivity, the electrodes were connected to either an electrometer or impedance analyzer by a computer-controlled data acquisition system. The computer remotely controlled the operation of the electrometer or impedance analyzer and collected data used to calculate the dielectric constant and resistivity of the coating. The temperature of the coated coupon was measured with a thermocouple which was also read by the data acquisition system. Data were collected while the furnace was slowly heating or cooling the sample fixture, which was located in the isothermal zone of the furnace.

\section{Results and Discussion}

Coatings were deposited for all powders and plasma-spray process conditions except when powder "c" was sprayed using the higher velocity gun set-up and at the lowest power level $(\sim 25 \mathrm{~kW})$. As-sprayed average thicknesses for coatings sprayed using powders "a" and " $\mathrm{b}$ " ranged from 373 to $593 \mu \mathrm{m}$. Dielectric constants ranged from about 4 to 8 , increasing by less than an order of magnitude over the test temperature range. As shown in Figure 1, the dielectric constant, $K$, measured for coatings sprayed using powder "a" and the lower velocity gun configuration ranged from about 5 to 7 . The hysterisis shown in the heating and cooling curves in this figure was also evident in electrical resistivity data for all coatings. Since resistivities measured during furnace heating were typically higher, resistivity data measured during the furnace cool-down cycle for selected coatings are shown in Figures 2 through 7. The first four of these figures (2-5) show resistivities measured 
over a temperature range of 200 to $600^{\circ} \mathrm{C}$ for coatings sprayed using each of the three powders. Data obtained below $200^{\circ} \mathrm{C}$ are not shown due to the length of time required to minimize scatter effects in this temperature range, and the lesser importance of these data in evaluating relative coating performance Since particle velocities could not be measured for this study, only the abbreviations "LV" and "HV" are used in the figures to indicate that plasma-spraying was performed using the "lower" or "higher" velocity gun configurations, respectively.

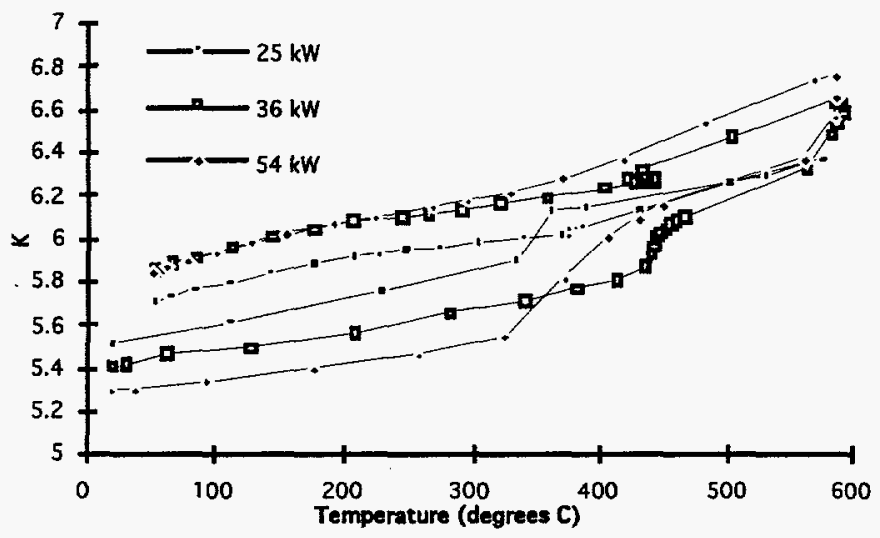

Figure 1: Effect of temperature cycling on dielectric constant for alumina coatings plasmasprayed using powder " $a$ " and an "LV" gun at various power levels.

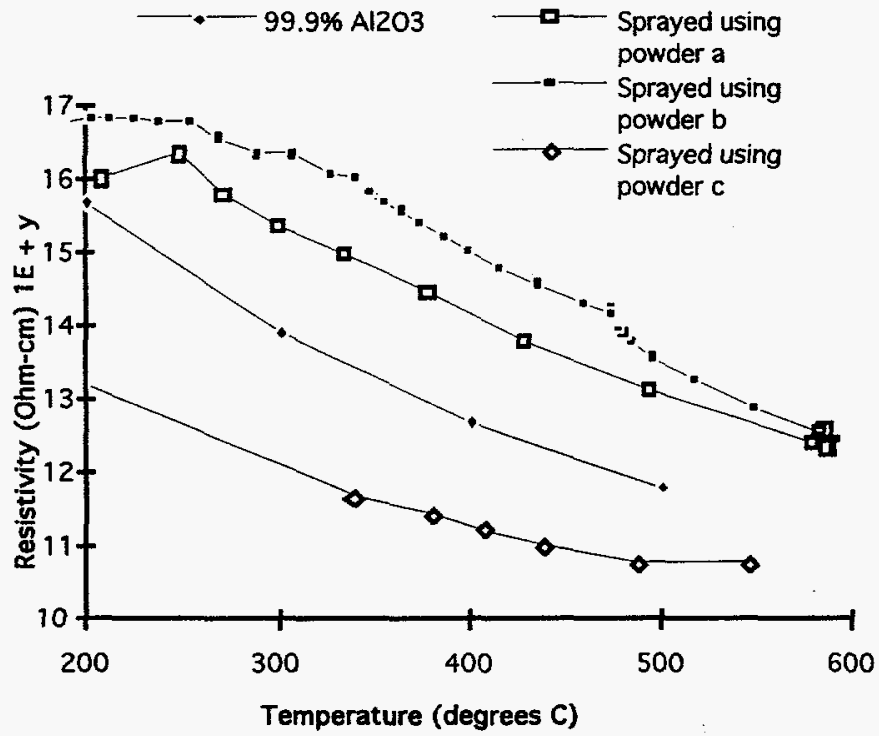

Figure 2: Variation in electrical resistivity with temperature for bulk alumina vs. coatings plasmasprayed using an "LV" gun \& $\sim 55 k W$.

In Figure 2, resistivity data measured for the coatings sprayed using the "LV" gun set-up are plotted along with data reported for $99.9 \%$ pure bulk alumina with unspecified impurities [12]. Electrical resistivities measured over most of the test temperature range for the coating sprayed using powder " $b$ " are about an order of magnitude higher than those for the coating sprayed using powder "a," except at the upper end of the test temperature range where measured resistivities for the two coatings are similar. As shown in Figure 3 and under four of the six different spray conditions evaluated, the higher purity powder " $b$ " yielded higher resistivity coatings overall than those sprayed using powder "a." Since powder "b" has a somewhat lower overall impurity content than powder " $a$," these results would be predicted based on composition alone excluding microstructural effects. Consistently lower resistivities were measured for coatings sprayed under all conditions using powder "c," which probably reflects the relatively high wt\% of sodium and other impurities in the powder. Although the highest purity powder corresponded to relatively higher resistivity coatings under most spray conditions, coatings sprayed using powder " $a$ " and the " $\mathrm{LV}$ " gun at the lowest power level, as well as the "HV" gun at the highest power level, exceeded resistivities measured for powder " $b$ " coatings sprayed under the same process settings (Figures 4 and 5). At the highest test temperature (about $600^{\circ} \mathrm{C}$ ), the highest value measured for all the coatings corresponded to the slightly lower purity powder "a." These varying results show the importance of careful selection and control of process variables to optimize electrical resistivity in very high purity, low alkaline content alumina coatings. An additional example is shown in Figures 6 and 7, where electrical resistivities were considerably lower when powder " $a$ " was sprayed using an intermediate power level for both the "LV" and "HV" guns. To explain these effects, however, further statistically designed parameter studies are needed to relate power level and gun configuration to the variables such as particle temperature, velocity, and cooling characteristics. The relationship of these variables to features such as splat morphology and adhesion/cohesion, phase formation, and porosity could then be better related to compositional distribution and measured electrical properties.

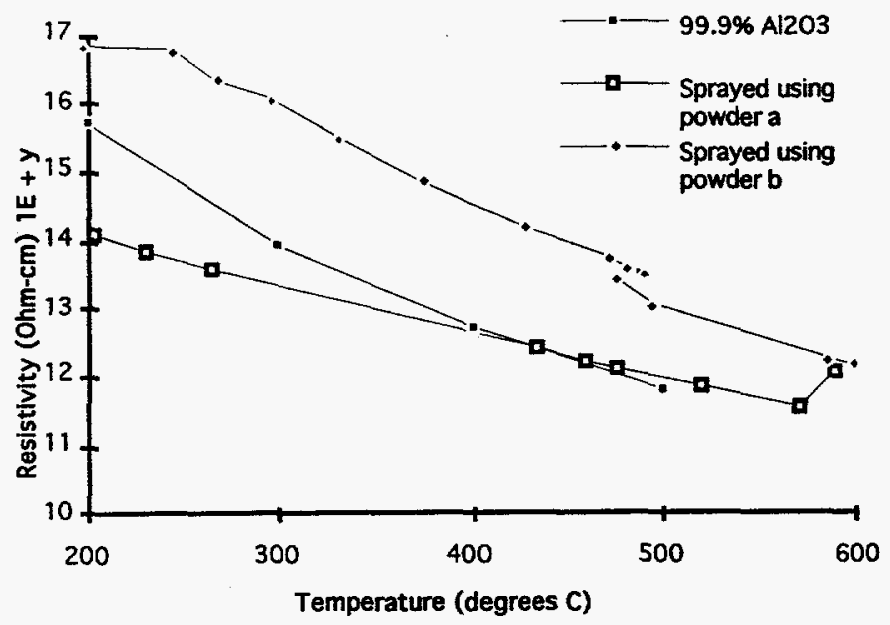

Figure 3: Variation in electrical resistivity with temperature for bulk alumina vs. coatings plasmasprayed using an "HV" gun and $-26 \mathrm{~kW}$. 
In addition to electrical properties, the only physical characteristic of the coatings to which the gun set-up and power variation could be related in this preliminary study was phase content. Coatings deposited for each powder under all spray conditions contained $\alpha$ and $\gamma \mathrm{Al}_{2} \mathrm{O}_{3}$. X-ray diffraction of the two sets of coatings corresponding to powders "a" and " $\mathrm{b}$ " revealed only these two phases in varying amounts. Coatings sprayed using the lower purity powder "c" also contained peaks that could not be identified as any phase containing aluminum, oxygen, or carbon. Since standard patterns for transition aluminas are poor-quality standards, however, these peaks may have been associated with other transition alumina phases. In all of the coatings, larger amounts of the high temperature $\alpha$ phase were obtained when the "HV" gun set-up was used. Power level had a secondary influence, with the relative amount of $\alpha$ tending to decrease as power level increased for each gun set-up. These results may be due to incomplete melting of the feed material that has been associated with increased $\alpha$ in thermally-sprayed alumina [11]. Although the relative amount of the stable alpha phase versus the lower temperature $\gamma$ phase varied consistently with systematic process variations, the relative amounts did not appear to correlate with higher or lower measured electrical resistivities in coatings sprayed simultaneously under the same conditions.

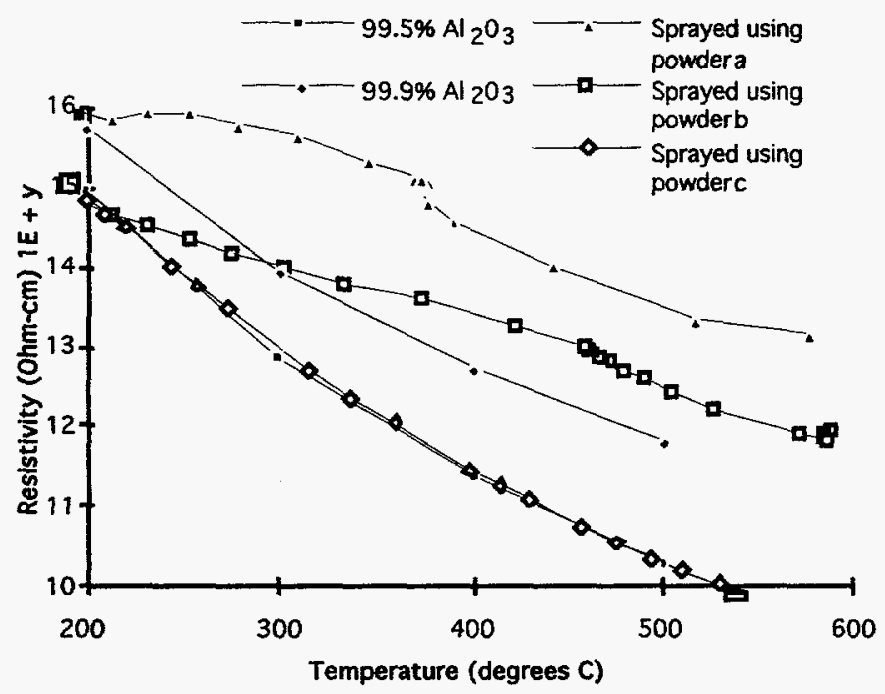

Figure 4: Variation in electrical resistivity with temperature for bulk alumina vs. coatings plasmasprayed using an "LV" gun and $\sim 25 \mathrm{~kW}$.

Relative to the data reported for $99.9 \%$ bulk alumina plotted in Figures 2 through 5, and data for $99.5 \%$ bulk alumina plotted in Figure 4, all coatings corresponding to the two highest purity powders (except for powder "a" sprayed using the "HV" gun and an intermediate power) show comparable or higher resistivities for all spray conditions. While a direct comparison based on composition cannot be made between the coatings and bulk alumina samples, the data indicate that significant amounts of impurities detrimental to electrical behavior are not introduced by the spray process such that the overall coating purity is reduced below that of the lowest purity bulk alumina. These results also suggest that higher electrical resistivity in thermally-sprayed material versus bulk material with the same or lower impurity content may be associated with coating microstructural features such as splat boundaries, fine grain structure, microcracks, multiple phases, and porosity that create a more complex compositional distribution and conduction path for mobile ions. Interestingly, the resistivity curve for the coating corresponding to the $99.59 \%$ pure powder " $\mathrm{c}$ " (plotted in Figure 4) is nearly identical as the curve plotted for $99.5 \%$ bulk alumina over the same temperature range. This suggests that there is a threshold impurity level above which adjustment of spray variables may have much less effect on ionic conduction in the resultant coating.

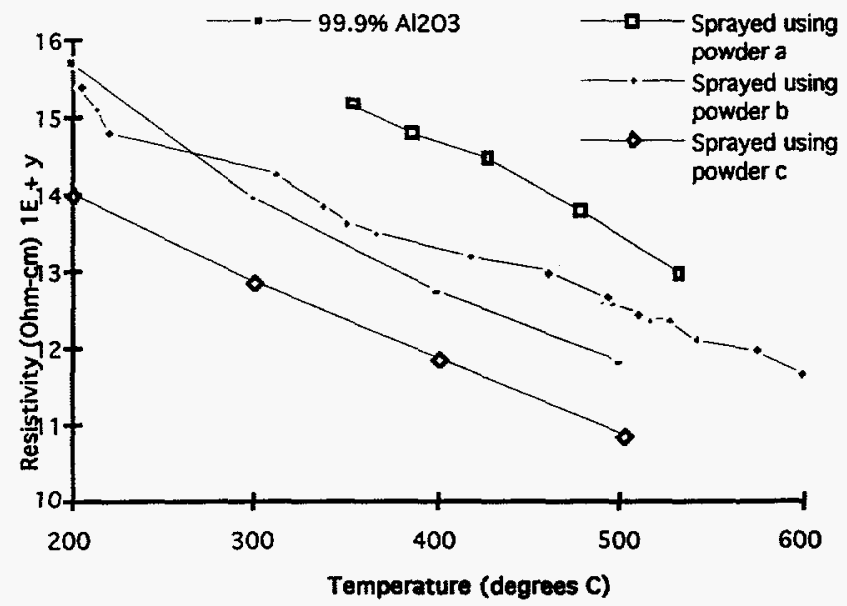

Figure 5: Variation in electrical resistivity with temperature for bulk alumina vs. coatings plasmasprayed using an "HV" gun \& $\sim 60 \mathrm{~kW}$.

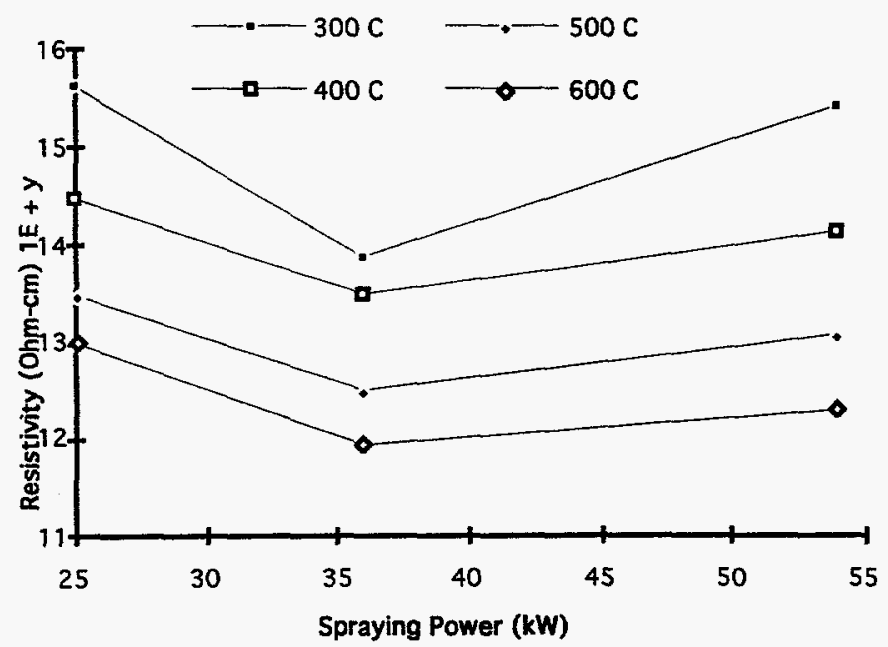

Figure 6: Variation in electrical resistivity with spray power level for a coating plasma-sprayed using powder "a" and an " $\mathrm{LV}$ " gun. 


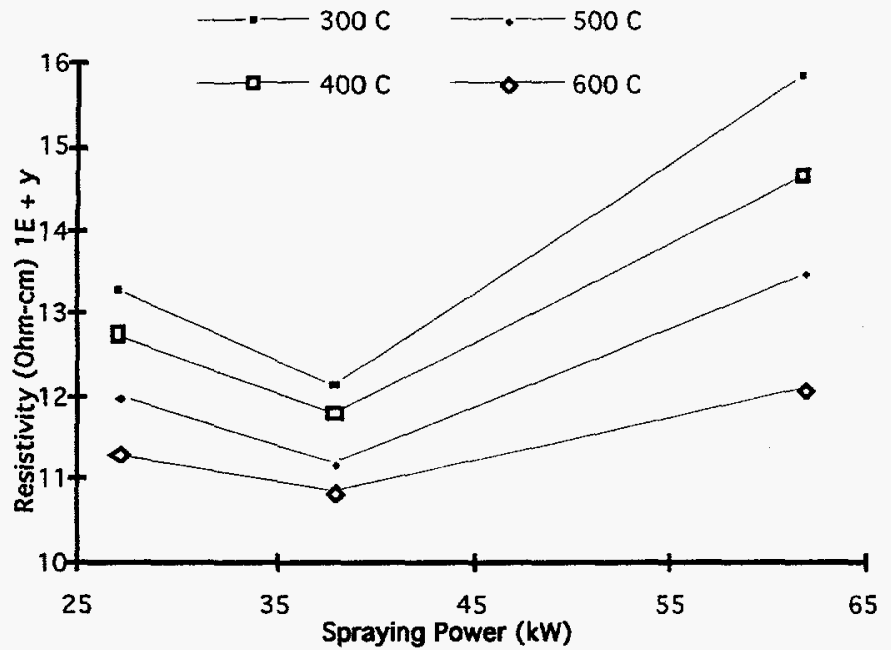

Figure 7: Variation in electrical resistivity with spray power level for a coating plasma-sprayed using powder "a" and an "HV" gun.

\section{Conclusions}

Electrical resistivities and dielectric constants were measured over a 20 to $600^{\circ} \mathrm{C}$ temperature range and compared for coatings plasma-sprayed using several high purity $\mathrm{Al}_{2} \mathrm{O}_{3}$ powders, two different gun configurations, and several power levels. Dielectric constants of selected coatings increased by less than an order of magnitude over the test temperature range. Electrical resistivity data corresponding to the limited range of process variables indicate that overall powder composition had the primary influence on high temperature resistivity. However, the variation in relative resistivities of coatings sprayed using the two highest purity powders shows the importance of careful selection and control of spray process conditions in optimizing coating electrical resistivity. Phase contents resulting from varying the gun configuration and power level did not appear to be a major controlling factor on the measured electrical resistivities. To improve the potential for controlling, optimizing, and reproducing electrical properties in plasma-sprayed alumina, further statistically designed experimental studies are needed which relate measured variables to coating electrical behavior and specific physical properties.

\section{Acknowledgments}

- Funding for this project was provided through a Cooperative Research and Development Agreement (CRADA \# SC92-1082) with SEMATECH. Additional support was provided by the Oak Ridge Centers for Manufacturing Technology.

The authors would like to thank K.R. Forbes and D.R. Wright of SEMATECH for technical guidance over the course of the project. Special thanks are also expressed to the following contributors from Oak Ridge National Laboratory:
C.J. Remenyik for assistance with electrical properties testing development; M.E. Garrison, T.A. Marlar, L.T. Ratcliff, and $\mathrm{J}$. Williams for thermal spray materials preparation and processing; S. Misture for X-ray diffraction work; J.E. Hardy and C.F. Leitten, Jr. for programmatic guidance; and D.O. Hobson for reviewing the manuscript.

\section{References}

1 Singer, P., "Electrostatic Chucks in Wafer Processing," Semiconductor International, 18 (4), 57-64 (1995).

2 Field, J., "Electrostatic Wafer Clamping for NextGeneration Manufacturing," Solid State Technology, 37 (9), 91-98 (1994).

3 Forbes, K., "Electrostatic Chuck (ESC) Benchmarking Report \#2," SEMATECH Technology Transfer Document 94082488A-ENG (1994).

4 Forbes, K., "Current Issues in Electrostatic Chuck Design For Etch Applications," 21st Plasma Technology Seminar, Tegal Corporation, 43-57 (1995).

5 Miyayama, M., K. Kuomoto and H. Yanagida, "Engineering Properties of Single Oxides," pp 748-757, ASM Engineered Materials Handbook, Vol. 4, ASM International, Materials Park, OH (1991).

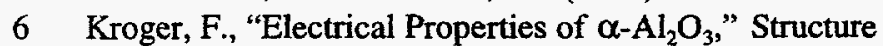
and Properties of $\mathrm{MgO}$ and $\mathrm{Al}_{2} \mathrm{O}_{3}$ Ceramics, Advances in Ceramics, Vol. 10, American Ceramic Society (1984).

7 Mizusaki, J., S. Tsuchiya, K. Waragai, H. Tagawa, Y. Arai and Y. Kuwayama, "Simple Mathematical Model for the Electrical Conductivity of Highly Porous Ceramics," J. Amer. Ceram. Soc., 79, 109-113 (1996).

8 Pawlowski, L., "Microstructural Study of PlasmaSprayed Alumina and Nickel Chromium Coatings," Surface and Coatings Technology, 31, 103-116 (1987).

9 Harris, D., "Selected Applications" p 18-22, course manual on Thermal Spray Technology, ASM International, Materials Park, OH (1992).

10 Swindeman, C., W. Murray, R. Seals, M. Cooper and K. Forbes, "Investigation of Thermally-Sprayed Coatings for High-Temperature Electrostatic Chucks (ESCs)," SEMATECH Technology Transfer Document 95102997A-ENG, 1995.

11 McPherson, R., "On the Formation of ThermallySprayed Alumina Coatings," Journal of Materials Science, 15, 3141-3149 (1980).

12 Material properties, VSMF Coors catalog, Coors Ceramics Co. Structural Division. 